Article - Human and Animal Health

\title{
Evaluation of Depressive and Anxious Behavior with the Use of Propranolol in Melanoma-Bearing Mice
}

\author{
Juliana Berton ${ }^{1}$ \\ https://orcid.org/0000-0002-8758-8921
}

Tamara Nascimento Ferreira ${ }^{1}$

https://orcid.org/0000-0002-7480-6678

\author{
Marcelo Machado Ferro ${ }^{3}$ \\ https://orcid.org/0000-0003-2939-072X \\ Giovani Marino Favero ${ }^{4^{\star}}$ \\ https://orcid.org/0000-0002-1946-3262
}

\section{Nadja Pereira Santos ${ }^{2}$ \\ https://orcid.org/0000-0002-3440-6450}

${ }^{1}$ Ponta Grossa State University/Central-West State University, Postgraduate Program in Pharmaceutical Sciences, Paraná, Brazil; ${ }^{2}$ Centro de Ensino Superior dos Campos Gerais, Ponta Grossa, Paraná, Brazil, ${ }^{3}$ Ponta Grossa State University, Biological and Health Sciences Division,Paraná, Brazil; ${ }^{4}$ Ponta Grossa State University, Biological and Health Science Multidisciplinary Laboratory, Paraná, Brazil.

Editor-in-Chief: Paulo Vitor Farago

Associate Editor: Paulo Vitor Farago

Received: 2020.07.03; Accepted: 2020.08.09.

*Correspondence: gmfavero@uepg.br. Telefax: + 5542 3220-3002. (G.M.F.).

\section{HIGHLIGHTS:}

- Tumor progression and anxiety and depression behaviors under evaluation during propranolol use in murine melanoma.

- Evaluation of anxiety and depression through forced swimming behavior tests, elevated plus maze, open field and marble-burying test.

\begin{abstract}
Melanoma, a severe form of skin cancer, has rapid growth and has been prone to behavioral disorders that worsen the patient's prognosis and survival. Among these psychic disorders can occur anxiety and depression, in addition to cognitive deficit. In order to try to elucidate the neuropsychological disorders that occur in melanoma, the objective of this study was to evaluate propranolol in tumor progression and in anxious and depressive behaviors in an animal model with melanoma. B16F10 cells were injected into C57BL6/J mice subsequently treated with propranolol at doses of $1.43 \mathrm{mg} / \mathrm{kg}$ and $5.71 \mathrm{mg} / \mathrm{kg}$ and evaluated for tumor growth and in open field, forced swimming, elevated plus maze and marble-burying test at initial time and consolidated tumor. As a result, the group treated with propranolol at a dose of $5.71 \mathrm{mg} / \mathrm{kg}$ showed less tumor growth. In the initial behavioral tests, melanoma altered the animals' motility, but anxious behavior was not detected. Depressive behavior was detected in the forced swimming test in the two doses of the treatment used. When taking time with consolidated tumor, there was a reduction in the locomotor activity of the animals in the open field test, impairing the analysis of anxious and depressive behavior. The data suggest that there was a reduction in the progression of melanoma, there was no anxious behavior in the animals, only the depressive behavior and the use of propranolol did not improve the evaluated behavior.
\end{abstract}

Keywords: melanoma; depression; anxiety. 


\section{INTRODUTION}

Melanoma is the most aggressive skin cancer and constitutes a worldwide public health demand [1]. Case numbers have increased in recent decades and cause $80 \%$ of skin cancer deaths. It is a disease resistant to most existing therapies, has a poor prognosis for the patient and a short survival time, making its investigation crucial [2].

Being the etiology of multifactorial melanoma, cases related to heredity represent 5 to $10 \%$ of the total records [3], but other risk factors such as: light skin, sun exposure and light must also be considered excess ultraviolet, and additionally the incidence in immunocompromised and patients with high levels of stress at work has been considered [4].

Regarding the ability to cause metastases, melanoma is specialized, being present in most deaths of skin cancer patients [5]. Due to its anaplasia, melanoma can produce catecholamines, and it is possible to increase the responses of the sympathetic nervous system, resulting in other pathologies associated with cancer, such as psychic disorders.

Research on interventions with sympathetic activation components, or the use of $\beta$-blocking agents, may represent new strategies to slow the progression of malignancy and assist in the quality of life of cancer patients [6].

It is still unclear to what extent melanoma affects the quality of life of patients from a psychological point of view [7], however the central and peripheral nervous systems can be significantly compromised. Neurological signs and symptoms are present in about $30 \%$ to $50 \%$ of patients who go to neurological consultation in oncology service hospitals [8].

Psychoneuroimmunology lists factors of behavior and psychological stress as agents that influence health, including cancer [6]. Studies show that symptoms of depression and anxiety have a higher incidence in cancer patients when compared to other types of chronic diseases. Anxiety and depression can alter physical, emotional and cognitive functioning [9]. In cancer patients the early diagnosis of these pathologies is challenging, and therapeutic interventions are difficult [10]. Impairment of quality of life can occur and correlation with physical symptoms [9].

Beta-blockers have been used for performance anxiety in order to block autonomic signals that cause social fear [11], especially propranolol [12], which has an action on adrenergic $\beta 1$ and $\beta 2$ receptors, which in physiological activity they are activated through catecholamines, so that the fight or flight response in the sympathetic nervous system can be given[13]. These same receptors are also involved in the cellular processes of cancer: angiogenesis, metastasis, progression, invasion and apoptosis[14], and are the target receptors for $\beta$-blockers, preventing the binding of catecholamines when they are present[15]. In this sense, research using $\beta$-blocking agents can be considered to slow the progression of the tumor and assist in the quality of life of individuals with cancer [6].

Due to the difficulties of studying symptoms such as anxiety and depression in human patients with tumors, animal models of human psychiatric diseases are among the valuable tools to investigate neurobiology and etiology in these states [16]. In studies, the detection of anxious or depressive conditions is carried out with the application of behavioral models, such as: elevated plus maze, forced swimming, open field and marble-burying test. These tests assess the animal's emotional responsiveness, in which they exhibit expected behaviors, whether they explore the environment or may be aversive [17].

Assessments of anxiety states resulting from stress in rodents are mostly assessed by the behavioral test of the elevated plus-maze, however the marble-burying test can also obtain reliable results for drugs or anxiety conditions; in the short and long term, being useful to assess the gradual progression of stress [18]. The open field test shows similarity in the reasoning regarding the environment exploration profile and adds the assessment of the animals' locomotion in the arena [17]. The forced swimming test is adequate to effectively assess classes of drugs or depressive conditions [19].

\section{MATERIALS AND METHODS}

\section{Experimental protocol}

The C57BL/6J mice (male, 20-25 g), with eight weeks of age, from the vivarium of our institution were used after prior approval by the Ethics Committee on Animal Experimentation of the State University of Ponta Grossa (protocol number 765/2014). The animals received the same food and water ad libitum and were kept at room temperature $\left(21 \pm 3^{\circ} \mathrm{C}\right)$ under a $12 / 12 \mathrm{~h}$ natural light cycle, with four animals per cage. Initially, the animals were divided into two primary groups. The first group composed of 13 animals did not receive the 
implantation of tumor cells, called the healthy control group. The second group composed of the rest of the animals received $5 \times 10^{4} \mathrm{~B} 16 \mathrm{~F} 10$ cells that were implanted subcutaneously. These animals were randomly divided into five groups containing twelve animals each group.

Five days after implantation, treatment was started and lasted for 15 days. Animals in the healthy control group and the control group with melanoma were given water during treatment, by gavage. The groups propranolol 10 and melanoma propranolol 10 were administered daily by gavage, a solution of propranolol in water at a dose of $1.43 \mathrm{mg} / \mathrm{kg}$. The propranolol $40 \mathrm{mg}$ and melanoma propranolol $40 \mathrm{mg}$ groups were administered a daily solution of propranolol at a dose of $5.71 \mathrm{mg} / \mathrm{kg}$ in water by gavage. The doses were calculated and adapted to the mouse through body weight and metabolism. The treatment time was selected due to previous studies carried out in our laboratory and due to the use of C57BL6/J, to take advantage of the rapid onset of melanoma and the short time between the appearance of metastases [20].

\section{Assessment of tumor growth}

On the fifth day after the implantation of tumor cells, the mice were evaluated for the appearance of the tumor on the animal's back. From the day the tumor became visible and palpable, a Digital Pachymeter (Marberg®) was used to determine the tumor measurements, necessary for calculating the tumor volume, according to the formula: Tumor Volume $=$ Longitudinal measurement $(\mathrm{mm}) \times[($ transversal measure $(\mathrm{mm})] 2$ $x 3 / 4 \mathbb{4}[21]$, being carried out daily until the 15 th day.

\section{Behavioral tests}

The behavioral tests were carried out at the Pharmacology Laboratory of the State University of Ponta Grossa in two time intervals, the first at the beginning of the treatment (fifth to eighth day), called time 1, which refers to the beginning of the development of the tumor and the second time taken, called time 2 at the end of treatment (twelfth to fifteenth day), considering consolidated tumor.

The behavioral tests used were open field, forced swimming, elevated plus maze and marble-burying test. The open field test is carried out in a box made of wood $(30 \times 30 \times 20 \mathrm{~cm})$ covered in black, the base of the box being divided into 25 equal squares painted in white that assesses locomotor and anxiety activity [22], being the animal's walking around the periphery considered a measure of locomotor activity and walking in the center of the open field, a more selective measure for anxiety [23].

In the forced swimming test [24], the animal is exposed to stress with no possibility of escape. It is placed in a cylindrical container containing water to try to escape from this environment and unfavorable situation and then chooses to remain immobile. Although it is difficult to assess the neurological processes of human depression, the analogy of the forced swimming test with the disease is due to the behavioral findings found when antidepressants or antidepressant situations are administered; where immobility is reduced and escape attempts are increased [25].

The elevated plus maze is based on the exploration versus aversion conflict, based on the natural rejection of rodents to open spaces [26]. This wooden instrument consists of two open and two closed arms, raised by a platform. The elevated plus maze was developed for rats [27] and was validated for mice [28] as a model for assessing anxiety and locomotion. In this test, anxiolytics reduce the animal's natural aversion to open arms and encourage the exploration of those arms. Meanwhile, staying in closed arms is a behavior indicative of increased anxiety [29, 30].

In the marble-burying tested adapted from rats to mice [31] anxious and compulsive behaviors are evaluated [32], due to the behavior shown by rodents of burying hostile objects or harmful food. The marbleburying testwas carried out in a polyethylene box $(40 \times 34 \times 16 \mathrm{~cm})$, containing the bottom covered with a 5 $\mathrm{cm}$ layer of wood shavings. In this box 24 glass spheres were evenly distributed on the periphery.

\section{Statistical analysis}

The results were expressed as mean $\pm S D$ and the differences in mean values between groups were compared using ANOVA. When the differences were obvious $(p<0.05)$, the Tukey test was performed to compare the means. Probability values below 0.05 were considered statistically significant [33]. Data analysis was performed using GraphPad Prism (GraphPad Software, San Diego, CA, USA). 


\section{RESULTS}

According to the tumor volume determined, the $40 \mathrm{mg}$ propranolol group showed a statistically significant difference when compared to the control groups and $10 \mathrm{mg}$ propranolol group, under the experimental conditions used, as can be seen in Figure 1.

About behavioral tests, in the open field test, the animals were evaluated for the number of total crosses, time spent in the center of the open field, time spent in the periphery and time to get up. At Time 1, regarding the length of stay in the center of the open field, there was a significant effect on the melanoma/propranolol interaction with $[F(2.72)=3.9266 ; p=0.02407]$ and there was no significant difference between the groups with melanoma treated with water or with propranolol at doses of 10 and $40 \mathrm{mg} / \mathrm{kg}$ and healthy groups treated with propranolol at doses of 10 and $40 \mathrm{mg} / \mathrm{kg}$, as shows Figure 2.

In the forced swimming test the animals were evaluated for immobility time, swimming time and climbing time. At time 1, the immobility time was shorter in the healthy group treated with water, with the effect shown by propranolol $[F(2.70)=6.7865 ; p=0.00202]$, as shown in Figure 3 .

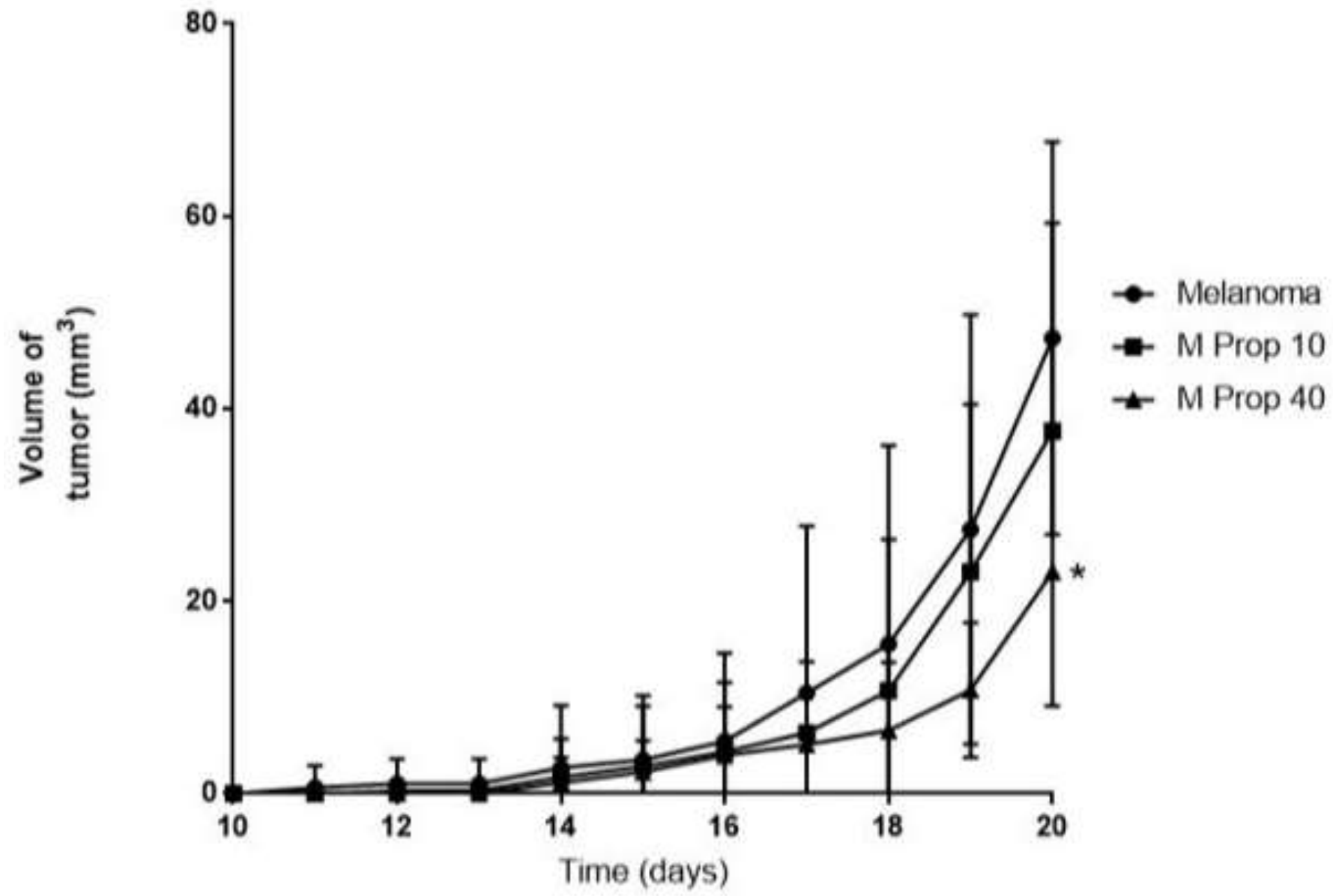

Figure 1. Evaluation of tumor volume.Treatment with vehicle (saline), propranolol 10 and $40 \mathrm{mg}$ in B16F10 tumors in C57BL6/J mice with melanoma ( $n=13 /$ group), for 15 days of treatmentstarted on the fifth day after cell implantation. ANOVA -1 VIA, Tukey post hoc, values expressed as mean \pm SEM, with * $p<0.05 \%$. 


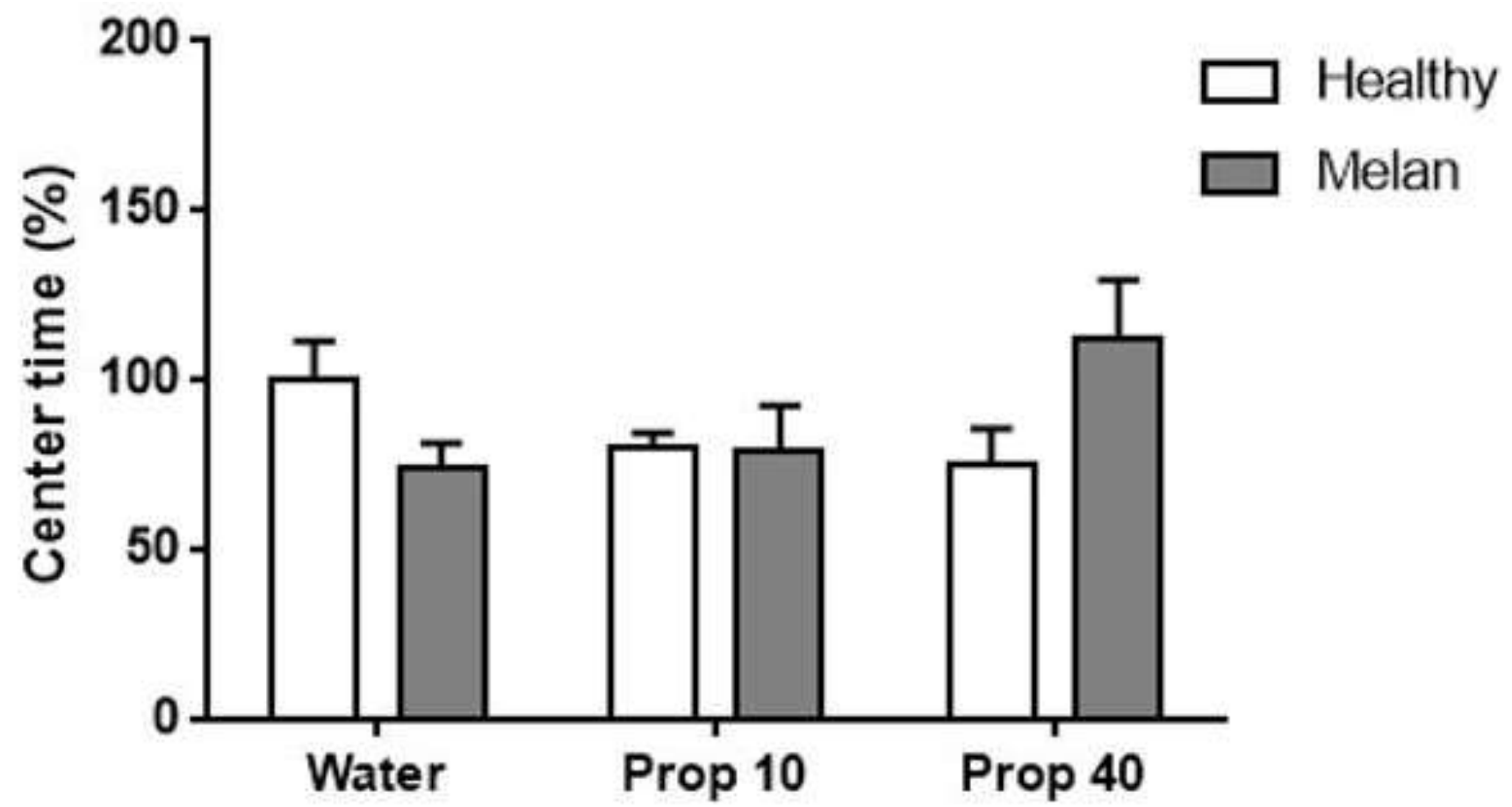

Figure 2. Time of stay at the center in Open Field Test (Time $1=5 \mathrm{~min}$ ).Performed with C57BL6/J mice ( $\mathrm{n}=13 / \mathrm{group}$ ), HEALTHY = absence of melanoma and Melan = Melanoma carrier, treated with water, propranolol $10 \mathrm{mg}$ and propranolol $40 \mathrm{mg}$. The results were analyzed with Two-Way-ANOVA, with post-hoc Newman-Keuls test, values expressed as mean \pm SEM, with * $p<0.05 \%$.

Swimming time at forced swimming test time 1, there was an effect of propranolol $[F(2.71)=7.6395$; $\mathrm{p}=0.00099$ ], with the melanoma group treated with propranolol at the dose of $40 \mathrm{mg}$, the healthy group treated with propranolol at the dose of $10 \mathrm{mg}$ and the healthy group treated with propranolol at the dose of $40 \mathrm{mg}$ with shorter swimming times than the healthy group treated with water, as shown in Figure 4.

In the elevated plus maze test, animals were evaluated for time spent in open arms, number of crosses in open arms, time spent with closed arms, number of entries in closed arms, number of crossings in the center, but there was no difference statistics between groups with melanoma or healthy in none of the parameters evaluated in time 1.

The behavior in the marble-burying test showed no statistical difference between the groups at Time 1.

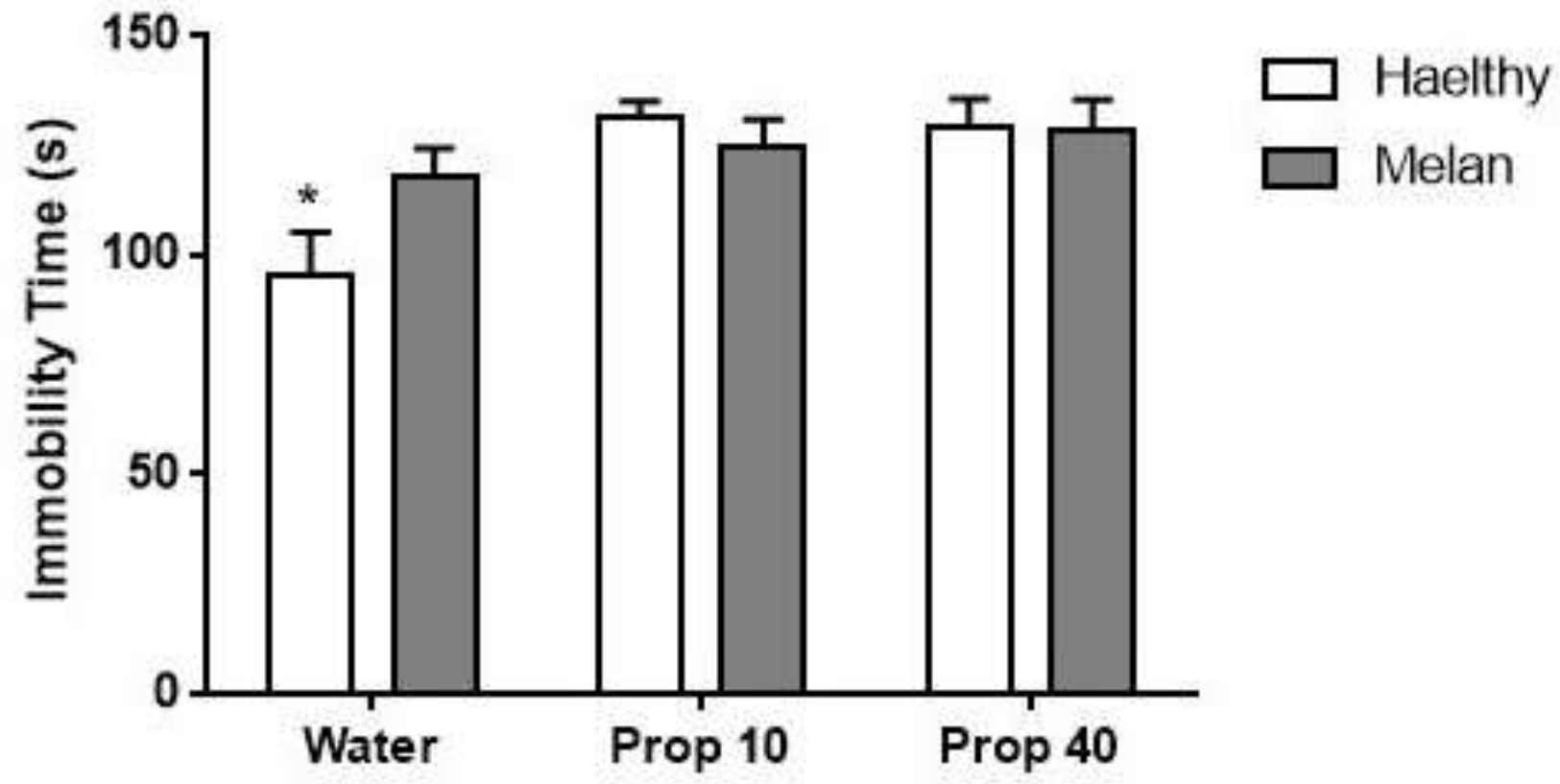

Figure 3. Immobility time (seconds) in the Forced Swimming Test (Time 1=5 min). Performed with C57BL6/J mice ( $n=13$ group), HEALTHY = absence of melanoma and MELAN = Melanoma carrier, treated with water, propranolol 10 mg and propranolol $40 \mathrm{mg}$. The results were analyzed with Two-Way-ANOVA, with post-hoc Newman-Keuls test, values expressed as mean \pm EPM, with ${ }^{*} p<0.05 \%$. 


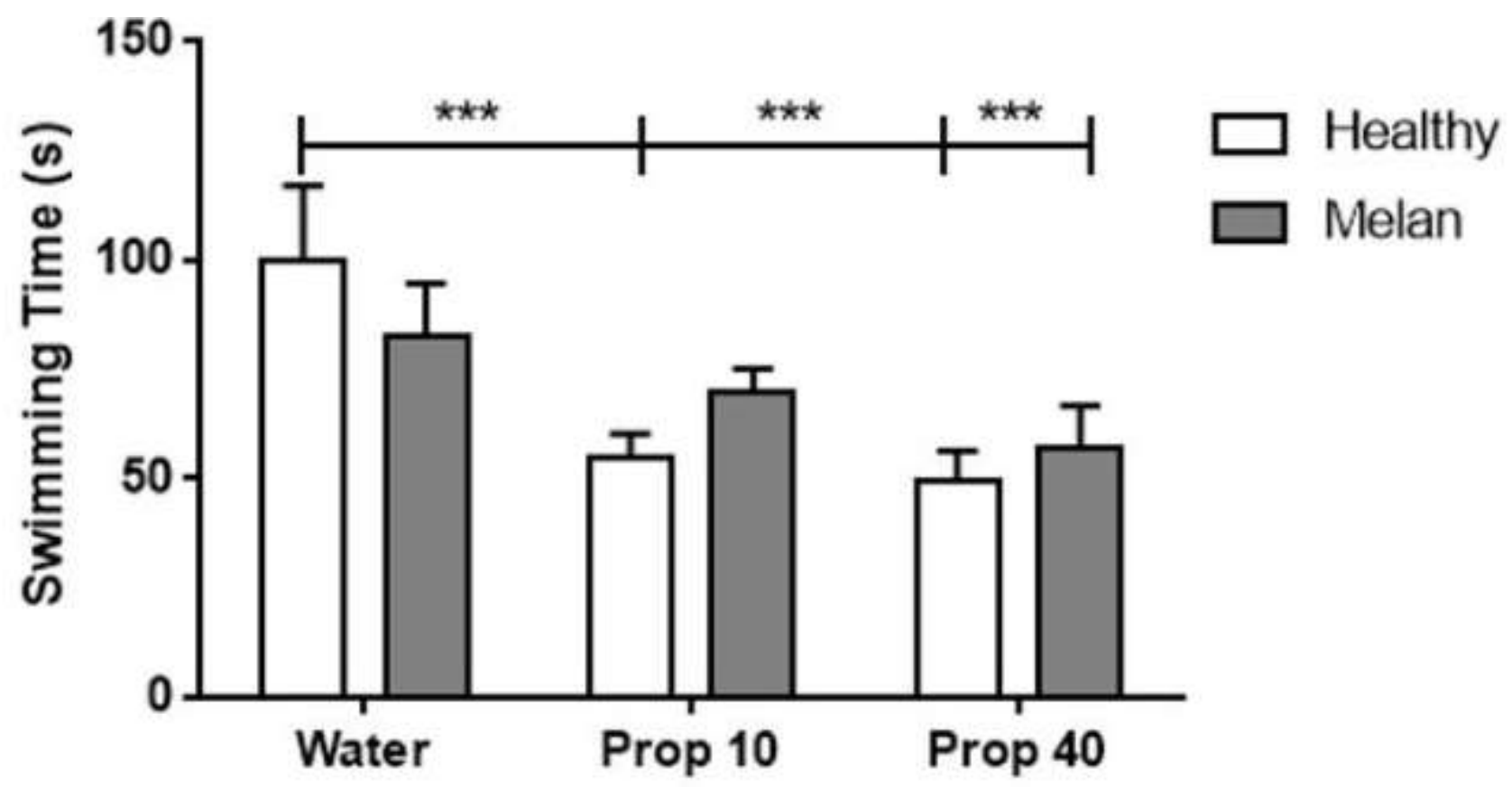

Figure 4. Swimming time (seconds) in the Forced Swimming Test (Time $1=5 \mathrm{~min}$ ). Performed with C57BL6/J mice ( $n=13$ /group), HEALTHY = absence of melanoma and MELAN = Melanoma carrier, treated with water, propranolol 10 $\mathrm{mg}$ and propranolol $40 \mathrm{mg}$. The results were analyzed with Two-Way-ANOVA, with post-hoc Newman-Keuls test, values expressed as mean \pm EPM, with ${ }^{*} p<0.05 \%$.

The results obtained in locomotor activity in the open field at time 2 can be seen in Figure 5. There was an influence of the propranolol factor on locomotion $[F(2.70)=4.9246, p=, 00998]$. The animals in the groups propranolol $10 \mathrm{mg}$ and propranolol $40 \mathrm{mg}$, melanoma propranolol $10 \mathrm{mg}$ and melanoma propranolol $40 \mathrm{mg}$ ambulated significantly less than the healthy ones treated with water.

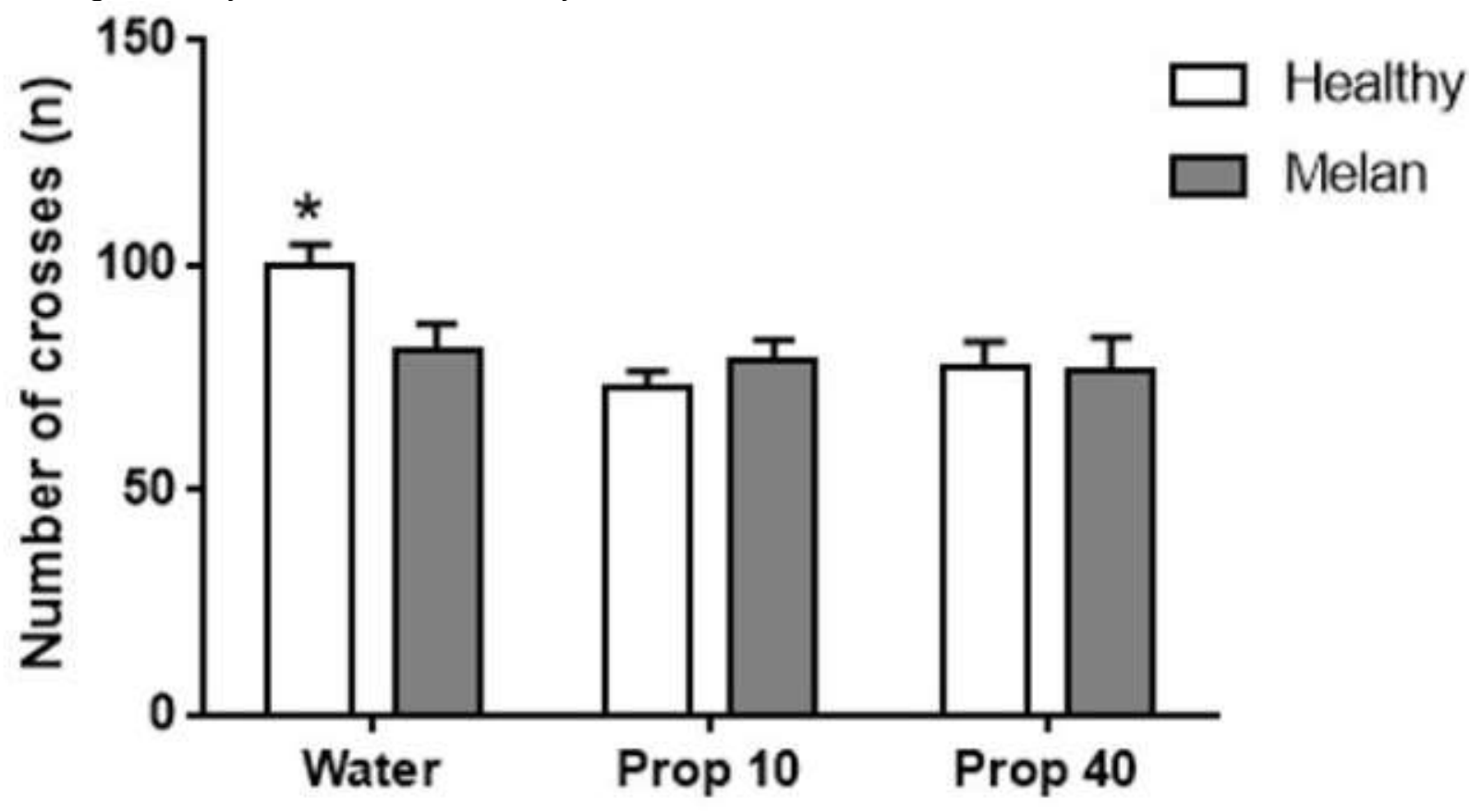

Figure 5. Number of total crossings $(n)$ in Open Field Test (Time $2=5$ min).Performed with C57BL6/J mice ( $n=13 / g r o u p)$, HEALTHY = absence of melanoma and MELAN = Melanoma carrier, treated with water, propranolol 10 mg and propranolol $40 \mathrm{mg}$. The results were analyzed with Two-Way-ANOVA, with post-hoc Newman-Keuls test, values expressed as mean \pm EPM, with * $p<0.05 \%$.

\section{DISCUSSION}

In addition to the causative agents such as fair skin, increased exposure to UV light, dysregulation of the immune system, the associated factor that contributes to the risk of developing melanoma is stress [4]. In 
response to stress, catecholamines, which are hormones released by the sympathetic nervous system, worsen the prognosis of the carrier, being related to accelerated tumor progression and decreased survival [34]. In the present study, tumor growth in the group with melanoma treated with $40 \mathrm{mg}$ of propranolol showed reduced growth compared to the group treated with propranolol at a dose of $10 \mathrm{mg}$ and control with melanoma treated with water. The results found corroborate the results obtained in other similar studies with a positive effect of treatment with propranolol in reducing tumor volume [15,35]. In tumor growth, the hypothesis that $\beta$ adrenergic signaling favors the progression of the tumor and its blocking can slow down its growth, gives the melanoma a positive response to $\beta$-blockers, whose targets are $\beta-1$ and $\beta-2$, as propranolol $[36,37]$. The nonselective antagonist propranolol has been widely used as an adjuvant in cancer therapy. Melanoma is a tumor with immunogenic properties and expresses $\alpha$ - and $\beta$-adrenergic receptors, with $\beta 1$ and $\beta 2$ identified in malignant melanoma [37] and which are activated by catecholamines during stress [38].

Behavior is an additional factor involved in the progression of melanoma. In humans, depression, anxiety and regretful decision-making behavior are present in most patients with tumors, with drug treatment necessary for $25 \%$ of these patients [39]. In animals with melanoma, through non-quantitative observations, there is the appearance that they behave differently from control animals, starting from this observation the interest in applying behavioral tests to measure these behaviors. The use of isogenic mice, such as C57BL6/J has the advantage of the rapid onset of melanoma and the short time between the appearance of metastases [40], as a disadvantage, due to this fact, the duration time of the experiment carried out in this study was determined. The use of male mice was preferred, due to the increasing trend in the incidence of melanoma in males and to subtract the physiological differences of the immune system, skin structure and sex hormones [41].

In behavioral models, animals are exposed to external stimuli capable of causing defensive behaviors and these behaviors can be antagonized by anxiolytic drugs; where anxiety can be measured as an emotional anticipation in response to the feeling of aversion, an uncontrollable behavior [42]. In addition, there are hypotheses that adrenergic neurotransmission receptors are involved in anxiety disorder in defensive reactions [43]. As for depressive behavior, it can present itself as: reactive depression, which occurs in response to an unfavorable fact, or endogenous depression, when it is a psychiatric disorder [44]. Depression and stress have been linked to tumor progression in clinical studies [38] and to the progression of cutaneous melanoma in vitro studies [45].

In the open field test, exploration movements without displacement, such as lifting or performing selfcleaning and locomotor movements are important in the evaluation of anxiolytic drugs [46]. In this study, locomotor movements were evaluated (time spent in the center, time spent in the periphery and number of total crossings) and as an exploratory activity, the time to get up. At time taken 1, considered an initial tumor, the groups showed no statistical difference in the number of total crosses. Since there is no significant effect on this parameter, the animals' lack of motor impairment is proven, and the results of the behavioral tests performed can be considered validated. Regarding the time spent in the center of the open field, there was an interaction between the melanoma and treatment with statistical significance, but there were no differences between the groups tested, which does not allow suggesting an anxiolytic effect in this behavioral test.

Another test used was the forced swimming test that is applicable to several classes of antidepressants [47], in the present study, in time 1, when the immobility time was determined, a difference in behavior was found, since all groups treated with propranolol and the control group melanoma obtained longer immobility times when compared to the healthy control treated with water, indicating a depressive-like effect. As consequence, the healthy control group showed the longest time in swimming behavior, being statistically different from the other groups that spent more time maintaining the immobility behavior. In this test, immobility is interpreted as hopelessness behavior, a common depressive symptom in patients, in addition to the fact that most antidepressants reduce immobility, stimulating active behavior [48].

It is possible that propranolol affects more than one signaling pathway, and that higher doses of this drug cause non-specific central sympatholytic effects, with the consequences, in addition to the hypotensive effect, also the decrease in central sympathetic nervous activity [15]. Additionally, the side effects of propranolol can be considered, such as depression and others: decreased energy, fatigue and low concentration, it is also believed that the beta-blocker propranolol may cause a disorder of organic mood, resulting in a depressed condition [49].

In the elevated plusmaze test, in this study, regarding the length of stay in the open arms, number of entries in the open arms, time in the closed arms, and number of entries in the closed arms, there was no difference between the groups tested. The permanence in closed arms in the elevated plusmaze represents 
the locomotor activity of the animals and can be used as confirmation of the locomotor activity of the open field test. This information confirms that there was no impairment in the locomotor activity of the animals at time 1 , due to the absence of difference between the groups both in the open field test and in the elevated plus maze test.

In the marble-burying test, no difference was found between groups at time 1, and treatment with propranolol was not able to interfere with the action marble-burying in healthy treated or carriers groups, portraying a non-anxious state due to the presence of melanoma.

At time 2, when the tumor is consolidated and the drug is used chronically, the behavioral tests were reapplied in order to assess the differences between the times and tumor evolution. The open field test, at time 2, revealed a decrease in locomotor activity in healthy groups and in groups with melanoma treated with propranolol and the group with melanoma treated with water, different from the healthy control group, which interferes in the analysis of results of behavior in time 2, not allowing to understand if the differences found are due to depressive or anxious behavior, or to the fact that motility is compromised. This result corroborates with another study [50] who, when performing treatment with $10 \mathrm{mg} / \mathrm{kg}$ of propranolol in mice, observed a decrease in locomotion and an increase in self-cleaning. Propranolol can cause symptoms similarto the depressive state [51], which may have contributed to reduced motility with chronic use of the medication. Another hypothesis considered would be that the consolidated tumor would have interfered with the animals' motor system, since the carrier control group also had reduced motility.

\section{CONCLUSIONS}

Considering our experimental data, there was a reduction in tumor volume in C57BL6/J mice with the treatment of propranolol at a dose of $40 \mathrm{mg} / \mathrm{kg} /$ day for 15 days.

Melanoma did not cause anxiety-like changes, but it did change motility. The animals showed typedepressive behavior in the forced swim test, possibly due to melanoma and treatment performed with propranolol at doses of $10 \mathrm{mg} / \mathrm{kg} /$ day and $40 \mathrm{mg} / \mathrm{kg} /$ day in time 1 .

At time 2, there was a reduction in the locomotor activity of the animals in the open field test, impairing the analysis of their behavioral effect with the consolidated tumor and there was no type-anxious behavior in the tests performed or the anxiolytic effect of the treatment carried out with propranolol in the doses of 10 $\mathrm{mg} / \mathrm{kg} / \mathrm{day}$ and $40 \mathrm{mg} / \mathrm{kg} / \mathrm{day}$.

Acknowledgements: This study was supported by Conselho Nacional de Desenvolvimento Científico e Tecnológico (CNPq), Brasilia, Brazil, CAPES (Coordenação de Aperfeiçoamento de Pessoal de Nível Superior), Brasilia, Braziland Fundação Araucária, Paraná, Brazil.

\section{REFERENCES}

1. Garcia, A, Lorente C,Elsner B, Avagnina A, Denninghoff V. Estado mutacional de BRAF y parámetroshistopatológicosen melanoma malignocutáneo. Medicina (B. Aires), Ciudad Autónoma de Buenos Aires. 2019;79(4):265-70.

2. Paluncic J. Kovacevic Z, Jansson P, Kalinowski D, Merlot AM, Huang M LH et al. Roads to Melanoma: Key Pathways and Emerging Players in Melanoma Progression and Oncogenic Signaling, Mol Cell.2016;1863(4):77084.

3. Erlich TH, Fisher DE. Pathways in melanoma development. G ItaldiDermatol Venereol.2018; 15(1):68-76.

4. Sinnya S; De'Ambrosis B. Stress and melanoma: increasing the evidence towards a causal basis. Arch Dermatol Res.2013;305(9):851-6.

5. Lee N, Barthel SR, Schatton, T. Melanoma stem cells and metastasis: mimicking hematopoietic cell trafficking? Lab Invest.2014; 94(1):13-30.

6. Yang EV. Role for catecholamines in tumor progression Possible use for $\beta$-blockers in the treatment of cancer. Cancer Biol Ther.2010; 101:30-2.

7. Beutel ME, Fischbeck S, Binder H, Blettner M, Brähler E, Emrich K. et al. Depression, anxiety and quality of life in long-term survivors of malignant melanoma: a register-based cohort study. PLoS One. 2015;10(1).

8. BaldwinKJ,Zivkovic SA, Lieberman FS. Neurologic Emergencies in Patients Who Have Cancer: Diagnosis and Management, NeurolClin. 2012; 30(1):101-28.

9. Salvetti, Machado CSP; Donato SCT, Silva AM. Prevalence of symptoms and quality of life of cancer patients. RevistaBrasileira de Enfermagem, Brasília.2020;73(2).

10. Moussas GI, Papadopoulou AG, Christodoulaki AG, Karkanias AP. Psychological and psychiatric problems in cancer patients: relationship to the localization of the disease. Psychiatrik. 2012;23(1):46-60. 
11. Fontanella, BJB. Ansiedade social e abuso de propranolol: relato de caso. Rev. Bras. Psiquiatr. São Paulo.2003; 25(4):228-30.

12. Nardi AE. O tratamento farmacológico da fobia social. Rev. Bras. Psiquiatr.1999;21(4):249-57.

13. Chang PY, Huang WY, Lin CL, Huang TC, Wu YY, Chen JH, Kao CH. Propranolol Reduces Cancer Risk: A Population-Based Cohort Study. Medicine.2015;94(27):1097.

14. SoodAK,Armaiz-Pena GN, Halder J, et al. Adrenergic modulation of focal adhesion kinase protects human ovarian cancer cells from anoikis. J.Clin. Invest.2010;120:1515-23.

15. Maccari S, Buoncervello M, RampinA, Spada M, Macchia D, Giordani L. Biphasic effects of propranolol on tumour growth in B16F10 melanoma-bearing mice. Br J Pharmacol.2017;174(2):139-49.

16. De Brouwer G,Wolmarans DW. Back to basics: A methodological perspective on marble-burying behavior as a screening test for psychiatric illness. Behav. Process. 2018;157:590-600.

17. Kalueff $A V$, Wheaton M, Murphy DL.What's wrong with my mouse model? Advances and strategies in animal modeling of anxiety and depression. Behav. Brain Res.2007;179:1-18.

18. Kedia S, Chattarji S. Marble burying as a test of the delayed anxiogenic effects of acute immobilization stress in mice. J Neurosci Methods.2014; 233:150-4.

19. Costa, A. P. R. Estudos da estrutura comportamental de camundongos nos testes de nado forçado e da suspensão pela cauda. Dissertação (Mestrado) - Universidade Federal de Santa Catarina, 2012.

20. Liu, Q Das, M, Liu, Y. Targeteddrug delivery to melanoma. Adv. Drug Deliv. Rev. 2018;127:208-21.

21. Kato $\mathrm{T}$, Sato K, Kakinuma $\mathrm{H}$, Matsuda $\mathrm{Y}$. Enhanced suppression of tumor growth by combination of angiogenesis inhibitor O-(chloroacetyl-marbamoylfumginol (TNP- 4700) and cytotoxic agents in mice. Cancer Res. 1994;54(19),5143-7.

22. Hall CS. Emotional behavior in the rat: I. Defecation and urination as measures of individual differences in emotionality. IntJ CompPsychol. 193418:385-403.

23. CruzAPM,Landeira-Fernandez, J. Modelos animais de ansiedade e o estudo experimental de drogas serotonérgicas. Em: J. Landeira-Fernandez e Sérgio Fukusima (org), Métodos em Neurociência. São Paulo: Manole.2012;192-217.

24. Porsolt RD, LePichon $\mathrm{M}$, JalfreM. Depression: a new animal model sensitive to antidepressant treatments. Nature.1977; 266(5604):730-32.

25. Martí J, Armario A. Effects of diazepam and desipramine in the forced swimming test: influence of previous experience with the situation. Eur. J. Pharmacol.1993;236(2):295-9.

26. Bourin $M$,Petit-Demoulière $B$, Dhonnchadha $B N$, Hascöet $M$. Animal models of anxiety in mice. Fundam.ClinPharmacol.2007;21:567-74.

27. Pellow S, Chopin P, File SE, Briley M. J.Neurosci. Methods.1985;14:149.

28. ListerRG. The use of a plus maze to measure anxiety in the mouse. Psychopharmacol.1987;92:180-5.

29. BadgujarVB,SuranaSJ. Anxiolytic effects of DolichandronefalcataSeem., Bignoniaceae, stem-bark in elevated plus maze and marble burying test on mice. Rev. Bras. Pharmacogn.2010;20(5):773-80.

30. Rico JL; BonutiR,Morato S. The elevated gradient of aversion: a new apparatus to study the rat behavior dimensions of anxiety, fear, and impulsivity. Braz. J. Med. Biol. Res., Ribeirão Preto, 2019; 52(11).

31. Broekkamp CL, Rijk HW, Joly-Gelouin D, Lloyd, KL. Major tranquillizers can be distinguished from minor tranquillizers on the basis of effects on marble burying and swim-induced grooming in mice. Eur. J. Pharmacol.1986;126(3):223-9.

32. De Brouwer G,Wolmarans DW. Back to basics: A methodological perspective on marble-burying behavior as a screening test for psychiatric illness. Behav. Process. 2018;157:590-600.

33. Granato D, AraújoCalado VM, Jarvis B. Observations on the use of statistical methods in Food Science and Technology. Food Res Int. 2014;55:137-49.

34. Moreno-Smith M, Lutgendorf, SK, Sood AK. Impact of stress on cancer metastasis. Future Oncol. 2010;6(12):186381.

35. Wrobel LJ, Gal FAL.Inhibition of Human Melanoma Growth by a Non-Cardioselectiveß-Blocker. J. Invest. Dermatol.2015;135(2):525-31.

36. Dal Monte M,Casini G, Filippi L, Nicchia GP, Svelto M, Bagnoli P. Functional involvement of b3-adrenergic receptors in melanoma growth and vascularization. J. Mol. Med. (Berl).2013;91:1407-19.

37. Kao J, Luu B. Can propranolol prevent progression of melanoma? JAAPA-J AM ACAD PHYS.2019;32(6):1-5.

38. Sanzo M, Colucci R, Arunachalam M, BertiS, Moretti S. Stress as a possible mechanism in melanoma progression. Dermatol. Res.Pract. 2010;(2):483-93.

39. Schuermeyer I, Maican A, Sharp R, Bena J, Triozzi PL, Singh AD. Depression, Anxiety, and Regret Before and After Testing to Estimate Uveal Melanoma Prognosis. JAMA Ophthalmol. 2016;134(1):51. 
40. LiuQ,Das M, Liu Y. Targeted drug delivery to melanoma. Adv. Drug.Deliv. Rev. 2018;127:208-21.

41. Roh MR, Eliades $P$, Gupta $S$, Grant-Kels JM, Tsao H. Cutaneous melanoma in women. Int. J.Women'sDermatol.2017;3:11-5.

42. Lacerda GFML, Ansiedade em modelos animais: efeito de drogas nas dimensões extraídas da análise fatorial. (Dissertação de Mestrado) - Universidade Federal do Paraná, 2006.

43. Souza, D. Participação de receptores noradrenérgicos na substância cinzenta periaquedutal dorsal na modulação de comportamentos defensivos relacionados à ansiedade. (Dissertação de Mestrado) - Ciências FarmacêuticasUniversidade Federal Do Espírito Santo, 2016.

44. Teixeira-Silva et al. Métodos para avaliar drogas antidepressivas. In: ALMEIDA, R. N., Psicofarmacologia: fundamentos práticos, Rio de Janeiro, Guanabara Koogan, p. 262-74, 2006.

45. Glasner A, Avraham R, RosenneE,Benish M, Zmora O, Shemer S. Improving survival rates in two models of spontaneous postoperative metastasis in mice by combined administration of a $\beta$-adrenergic antagonist and a cyclooxygenase-2 inhibitor. J.Immunol. 2010;184(5):2449-57.

46. Eilam D. Open-field behavior withstands drastic changes in arena size. Behav. Brain. Res.2003; 142:53-62.

47. Cryan JF, Lucki I. Antidepressant-like behavioral effects mediated by 5-hydroxytryptamine $2 \mathrm{C}$ receptors1. J. of Pharmacol. Exp.Ther. 2000; 295:1120-6.

48. Lucki I. The forced swimming test as a model for core and component behavioral effects of antidepressant drugs. Behav. Pharmacol. 1997;8:523-32.

49. Patten SB. Propranolol and depression: evidence from the antihypertensive trials. Can J. Psychiat. 1990;35(3):2579.

50. Sun $\mathrm{H}$, Mao Y, Wang J, Ma Y. Effects of beta-adrenergic antagonist, propranolol on spatial memory and exploratory behavior in mice Huaying. Neurosci. Lett. 2011;498:133-7.

51. BortolottoLA,Consolim-Colombo FM. Betabloqueadores adrenérgicos. Rev. Bras. Hipertens. 2009;16(4):215-20.

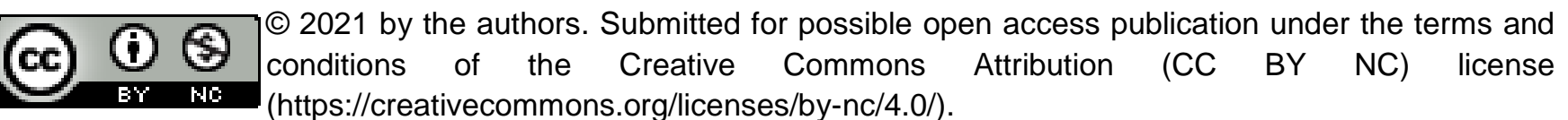

